Military Technical College

Kobry El-Kobbah, Cairo, Egypt

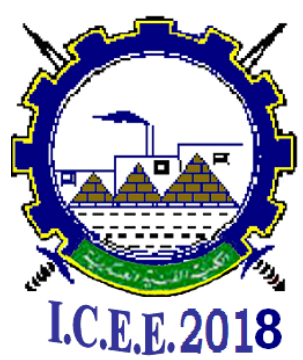

$9^{\text {th }}$ International Conference

on

Chemical \& Environmental

Engineering

3-5 April 2018

SMD-2

\title{
Food security: innovative approaches based on (bio) sensors and bioassays for the detection of mycotoxines
}

\author{
By \\ Jean Louis MARTY
}

\begin{abstract}
Mycotoxins are naturally occurring toxic, small chemical compounds (MW 700) that are produced as secondary metabolites by certain fungi contaminating food and feed, during crop growth or processing products. These compounds "once consumed by animals and/or humans" may lead to mycotoxicosis with symptoms of intoxication, causing substantial effects on animal and human health. According to the United Nations of Food and Agriculture Organization report, $25 \%$ of the word's food is significantly contaminated with mycotoxins. These contaminations can be occurred directly or indirectly. Indirect contamination of food and feed can take place when an ingredient have been previously contaminated with toxin producing fungi, while the fungi may be killed or removed during processing, the mycotoxin remains in the final product. Direct contaminations occur when the product is infected with toxigenic fungus inducing toxin liberation at different stage from the transformation process. Currently, more than 300 mycotoxins are known, and scientific interest is mainly on those that have been proven to be carcinogenic and/or toxic. These toxins include but not limited to ochratoxins (OT), aflatoxins (AF), tremorgenic toxins trichothecenes, fumonisins (F), patulin $(\mathrm{P})$, zearalenone $(\mathrm{ZON})$ and ergot alkaloids. The economic impact of mycotoxins includes perturbation of human and animal health, increased health care and veterinary costs, reduced livestock production, disposal of contaminated foods and feeds, and investment in research and applications to reduce severity. For these reasons, worldwide toxin contamination of foods and feeds presents a significant problem. In 1993, the WHO-International Agency of Research on Cancer (WHO-IARC, 1993) evaluated the carcinogenic potential of OT, AF, F, ZON, and trichothecenes. Naturally occurring AF was classified as a carcinogenic to human (Group 1) while OT and F were considered as possible carcinogens (Group 2B) with trichothecenes and $\mathrm{ZON}$ as non carcinogenic for human (Group 3). The European Commission has set maximum levels for these mycotoxins to protect human and animal health. To minimize the mycotoxins presence in the food supply, and to design strategies that would prevent contaminated commodities from entering food and feed processing facilities, attention must be focused on the methods of preventing mycotoxins formation at all levels of food chain. To meet this purpose, testing of the commodities is required to accomplish this
\end{abstract}


Military Technical College

Kobry El-Kobbah, Cairo, Egypt

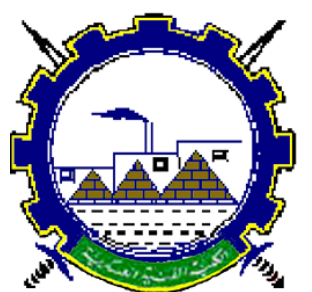

I.C.E.E.2018 $9^{\text {th }}$ International Conference

on

Chemical \& Environmental

Engineering

3-5 April 2018

process. This involves sample preparation and analysis using a quality testing procedure, which requires complicated and complex instrumentation, and qualified skilled person. In this context, an overview of recent progress in the domain of mycotoxins, their occurrence and detection in food and feed will be presented. The discussion will be particularly emphasized on the (bio) sensor and bioassays designs described for OTA, AF and ZON detection, as these biosensors architects provide general platform, and are also applied for the detection of other mycotoxins.

BAE-LBBM USR CNRS 376, Université de Perpignan Via domitia, 52 avenue Paul Alduy 66860 Perpignan Cedex France

Tel :+3368662254 or +33616814591 Fax:+33468662223 E-mail : jlmarty@univ-perp.fr 